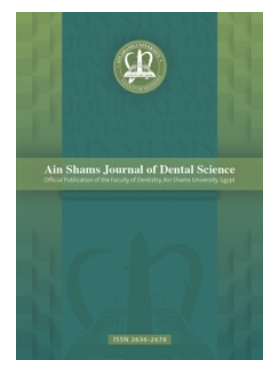

\title{
Retention Strength of Polyetheretherketone Crowns VS Zirconia Crowns Restoring Molar Teeth: An in Vitro Study
}

\author{
Hebat Allah Mohammad ab,*, Hesham Alansary ${ }^{\mathrm{c}}$, Lamia Kheiralla ${ }^{\mathrm{c}}$ \\ ${ }^{a}$ Masters Degree Student, Faculty of Dentistry, Cairo University \\ ${ }^{\mathrm{b}}$ Faculty of Dentistry, Misr International University (MIU). \\ ${ }^{c}$ Professor of Fixed Prosthodontics, Faculty of Dentistry, Cairo University \\ Corresponding author \\ Hebat Allah Mohammad Hassan Sayed \\ Telephone: 01000257528 \\ E-mail: hebatallah.mohammad@dentistry.cu.edu.eg
}

\begin{abstract}
Aim: This study was designed to compare the retention strength of monolithic CAD/CAM PEEK crowns to that of CAD/CAM monolithic YTZP-zirconia crowns, both resin-cemented to epoxy resin dies resembling lower molar teeth; after thermomechanical aging simulating 3 months of in-vivo service. Methodology: 22 identical epoxy dies, resembling the preparation of a lower second molar $\left(\mathbf{4 m m}\right.$ height, $6^{\circ}$ axial convergence and $\mathbf{1} \mathbf{m m}$-thick deep chamfer finish line), were produced by replicating one master stainless steel die via 22 polyvinyl siloxane impressions. The epoxy dies were randomly equally distributed into 2 groups ( $\mathbf{Z r}$ and $\mathbf{P}$ groups); 11 dies each. The first (control) group $(\mathbf{Z r})$ received CAD/CAM milled monolithic Y-TZP zirconia crowns (Katana ${ }^{\mathrm{TM}} \mathrm{ML}$ ), while the other group (intervention) received CAD/CAM milled monolithic PEEK crowns (breCAM.BioHPPTM). Two opposing, laterally projecting (mesial and distal) arms were included in the design of all crowns for the retention test. The fitting surfaces of crowns of both groups were sandblasted with 110- $\mathbf{\mu m}$ alumina particles. All crowns were cemented over their corresponding epoxy dies using the (handmixed) dual-cured, self-adhesive resin cement (RelyX ${ }^{\mathrm{TM}}$ U200) (3-kg seating force). Samples were stored in water incubator for 24 hours $\left(37^{\circ} \mathrm{C}\right)$; then, subjected to mechanical aging (37,500 cycles, $49 \mathrm{~N}$ load) with simultaneous thermocycling ( 300 cycles, 5-55 ${ }^{\circ} \mathrm{C}, 12$ s dwell time). Retention strength was evaluated by vertically pulling-up the crowns from their corresponding dies, through the pull-out test performed via a universal testing machine (UTM). Failure modes were then observed under digital microscope. The mean dislodgment force (retention strength) for each group was calculated, and statistically compared using Student t-test. Statistical analysis was performed with three-way ANOVA. Pair-wise comparison of groups was made with the Tukey test. Pearson's Chi-Square test was used to analyze the failure modes. Results: PEEK crowns group (P) demonstrated statistically insignificant higher retention strength $(\mathbf{1 7 1 . 2 8} \mathbf{N} \pm 26.30)$ than zirconia $(\mathbf{Z r})$ crowns group (150.40 $\mathrm{N} \pm 24.40)$. "Mixed" failure mode was predominant in both groups, followed by the adhesive "cement on crown" failure-mode.
\end{abstract}




\section{Keywords}

PEEK, Polyetheretherketone, CAD/CAM polymeric materials, multilayered monolithic zirconia, retentive strength, retention, tensile strength, pull-out test, pull-off test. 
Retention Strength of Polyetheretherketone Crowns VS Zirconia Crowns Restoring Molar Teeth: An in Vitro Study

\section{$\underline{\text { Introduction }}$}

Today, superior esthetic demands are no longer a luxury; there is a notable increase in esthetic consciousness and patients' anticipation for a naturally appearing dental restoration. Yttria-stabilized zirconia (Y-TZP) restorations are widely used owing to their exceptionally superior mechanical properties, even exceeding glass ceramics, combined with excellent biocompatibility and superior esthetics. Monolithic zirconia restorations were developed to avoid the problem of chipping of the veneering porcelain of zirconia ${ }^{[1,2]}$, especially for posterior area. Nonetheless, the excessively high hardness of monolithic zirconia (1200 $\mathrm{VHN})^{[3]}$ restorations caused severe wear to enamel $(270-360 \mathrm{VHN})^{[4]}$ antagonists and to the milling tools during processing ${ }^{[5,6]}$. This makes zirconia both labor- and cost-intensive to manufacture. Low-Temperature degradation (LTD) phenomenon ${ }^{[7]}$ and lack of etchability by routine acids, due to lack of glassy matrix ${ }^{[8,9]}$, are other drawbacks. PEEK (Poly-Ether-EtherKetone) is a biocompatible recently introduced derivative of the major family PAEK (PolyAryl-Ether-Ketone) of thermoplastic, high-performance polymers. PEEK possesses unique material properties that render it attractive for applications in dentistry. As for fixed prosthodontics, PEEK is representing a potential alternative to zirconia thanks to its comparable mechanical, physical and chemical properties, and notably lower surface hardness $(30 \mathrm{VHN})^{[3]}$. That is additional to its uniquely matching modulus of elasticity $(4-4.8 \mathrm{GPa})^{[3,10]}$ with the tooth $(15-83 \mathrm{GPa})^{[7]}$. Adequate retention is an inevitable prerequisite for long-term success of a fixed prosthesis. Prosthesis dislodgement falls among the most common causes of fixed prosthesis failure; and is rather the most common cause in many surveys ${ }^{[11,12]}$. Despite this, there are no studies in the peer-reviewed literature, to the authors' best knowledge, comparing the retention of PEEK to zirconia. Therefore, the current study was conducted to evaluate and compare the retention strength of PEEK monolithic crowns to monolithic zirconia crowns, after thermomechanical aging.

Being a polymer, PEEK was supposed to have better adhesion to resin cement. It was also assumed to get more influenced with the standardized sandblasting regimen than zirconia, due to its lower surface hardness value. Hence, it was hypothesized that PEEK would show higher retention values than zirconia.

\section{Material and methods:}

One master stainless steel die (Fig. 1) was specifically designed and milled using a bench lathe device ${ }^{1}$ to resemble a prepared lower second molar tooth $\left(6^{\circ}\right.$ axial taper, $\mathbf{4} \mathbf{~ m m}$ axial height, with a continuous 1-mm deep chamfer finish line and $\mathbf{2} \mathbf{~ m m}$ occlusal reduction) for receiving a full coverage single crown. 22 polyvinyl siloxane (PVS) impressions ${ }^{2}$ were made for the master stainless steel master die using a specially designed plastic cylinder as an impression tray (Fig. 2). Auto-polymerizing epoxy resin was mixed thoroughly according to the manufacturer's instructions and poured into the PVS impressions under vibration. 22 bubble-free epoxy resin replica dies were obtained (Fig. 3).

\footnotetext{
${ }^{1}$ BV20 Automatic feed bench lathe; Tengzhou Datong Machine Tool Co., China

${ }^{2}$ Zhermack $^{\mathrm{TM}}$ Elite HD+; Badia Polesine, Italy 


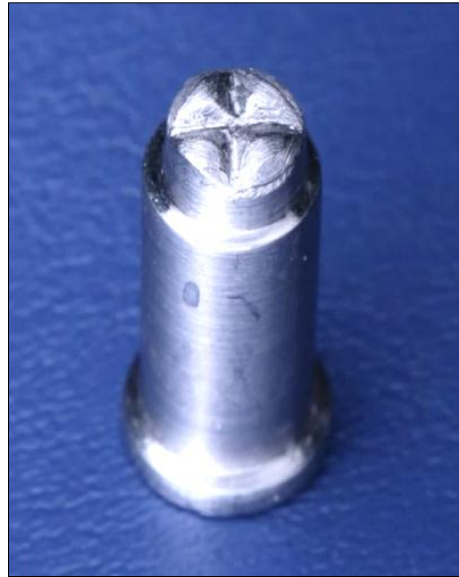

Fig. 1. Stainless steel master die resembling molar abutment preparation

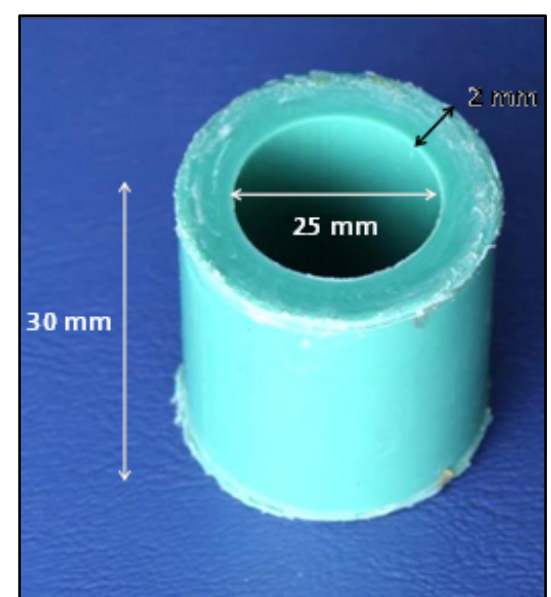

Fig. 2. Specially designed tray for PVS impression

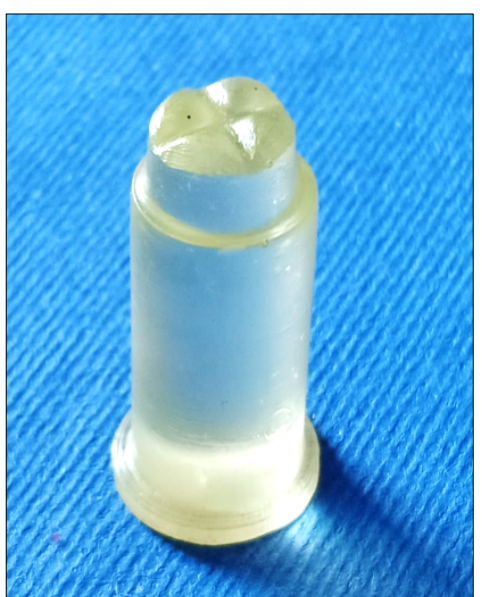

Fig. 3. Epoxy resin die (duplicated from master die)

A total of 22 resin dies were randomly divided into 2 equal groups; 11 dies each, as follows: Zirconia (Zr) group (control) and PEEK (P) group (intervention). An extra-oral optical scanner ${ }^{3}$ was used for scanning the epoxy replica dies using laser technology. For standardization purpose, the same design parameters of the CAD software ${ }^{4}$ were set for construction of all crowns of both groups $(\mathrm{Zr})$ and $(\mathrm{P})$ as follows: $\mathbf{5 0} \boldsymbol{\mu \mathrm { m }}$ virtual spacer, $\mathbf{1 . 5} \mathbf{~ \mathbf { m }}$ axial thickness and $\mathbf{2} \mathbf{~ m m}$ occlusal thickness, simulating contours of a lower second molar.

Two opposing wings (arms) were designed projecting from the mesial and distal surfaces of the crown, for holding the crown during the retention test (Fig. 4). All crowns were milled using the 5axis dry processing CAD/CAM dental milling machine ${ }^{5}$. New milling burs were placed prior to milling each group of 11 crowns. 11 slightly enlarged monolithic zirconia crowns by $\mathbf{2 0 . 6} \%$

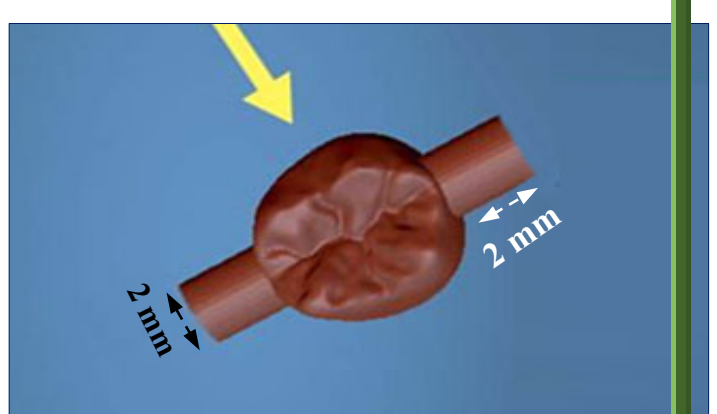

Fig. 4. Two opposing laterally projecti arms included in the crown design representing the control group $(\mathbf{Z r})$ were milled from partially sintered zirconia blanks ${ }^{6}$. They were then placed in a sintering furnace for final sintering, following the manufacturer's directions. The external surface of zirconia crowns were after that glazed following manufacturer's instructions. 11 monolithic PEEK crowns were milled from PEEK machining blanks ${ }^{7}$ representing the intervention group.

\footnotetext{
${ }^{3}$ Shera eco-scan 7 Scanner; Shera ${ }^{\mathrm{TM}}$, Lemförde, Germany

${ }^{4}$ ZirkonZahnn ${ }^{\mathrm{TM}}$.Modellier; Zirkonzahn GmbH, Gais, Italy

${ }^{5}$ Shera eco- mill 5x; Lemförde, Germany

${ }^{6} \mathrm{Katana}^{\mathrm{TM}}$ Zirconia multi-layered (ML); Kurary Noritake Dental Inc., Okayama, Japan

${ }^{7}$ breCAM.BioHPP ${ }^{\mathrm{TM}}$; Bredent GmbH \& Co.KG, Senden, Germany 
Retention Strength of Polyetheretherketone Crowns VS Zirconia Crowns Restoring Molar Teeth: An in Vitro Study

They were then finished and polished following the manufacturer's directions. The internal surfaces of all crowns of both groups $(\mathrm{Zr})$ and $(\mathrm{P})$ were sandblasted with 110- $\mu \mathrm{m}$ aluminum oxide particles at $0.3 \mathrm{MPa}$, from a standard distance of $10 \mathbf{~ m m}$ and vertically to the surface, for $\mathbf{1 0}$ seconds. Crowns were thoroughly air-sprayed after that, and then ultrasonically cleaned for 2 minutes and dried following the manufacturer's directions. All crowns of both groups were cemented over their corresponding dies using dual-cured self-adhesive MDPcontaining resin cement ${ }^{8}$ according to the manufacturer's instructions. Crowns were seated over their corresponding dies by maximum finger pressure. Then, a specially constructed cementing device was used to hold and subject the crowns to $3 \mathbf{~ k g}$ constant static axial load during cement setting. Initial brief light curing of 2 seconds was done, using a light-emitting diode unit ${ }^{9}$ (1000 - 1200 watt), and excess cement was removed using a scaler. Then, complete curing of the cement was done over each surface (occlusal, buccal, lingual, mesial and distal) for 20 seconds.

Thermomechanical loading was performed for all crowns using a computercontrolled multi-station chewing simulator ${ }^{10}$, integrated with thermocycling protocol operated on servo-motor. Chewing simulation was performed for $\mathbf{3 7 , 5 0 0}$ cycles with a load of $5 \mathrm{~kg}(49 \mathrm{~N})$ weight. Load was applied on the center of the occlusal surface of all crowns using a steel antagonist ball $(2.5 \mathrm{~mm}$ diameter) under standardized test parameters. This is nearly equivalent to $\mathbf{3}$ months of in vivo service time ${ }^{[13]}$. This was carried out in deionized water with simultaneous thermocycling for 300 cycles $\left(5^{\circ} \mathbf{C}\right.$ to $55^{\circ} \mathbf{C}$ every $60 \mathrm{~s}$, with a dwell time of $\mathbf{1 2}$ s) ${ }^{[13]}$.

Retention Measurements: Retention of the crowns to their resin dies was tested via the pull-off test utilizing a Universal Testing Machine ${ }^{11}$ (UTM) (Fig. 5). Each crown was dislodged along the long axis of its die by means of the UTM; with a loadcell of 5 kN, and crosshead speed of $1 \mathbf{~ m m} / \mathbf{m i n}$ (Fig. 6). Data were recorded using attached computer software ${ }^{12}$. Each crown was suspended to the upper movable compartment of the testing machine via double orthodontic wire loops (0.7 $\mathbf{~ m m}$ thickness) embracing the lateral arms designed in the mesial and distal surfaces of the crown (Fig. 6). The crowns were subjected to a slowly increasing vertical pull with crosshead speed of $1 \mathbf{m m} / \mathbf{m i n}$ until total dislodgment of the crowns. The set-up to hold the specimens was described by Sayed et al. (2017) ${ }^{[14]}$ and Aleisa et al. (2013) ${ }^{[15]}$; for even distribution of pulling tensile forces. The force at dislodgement for each specimen was recorded in Newtons $(\mathrm{N})$ and tabulated.

\footnotetext{
${ }^{8}$ RelyX ${ }^{\mathrm{TM}}$ U200; 3M ESPE, Seefeld, Germany

${ }^{9}$ Foshan $^{\mathrm{TM}}$; Being, China

${ }^{10}$ ROBOTA ${ }^{\text {TM }}$ Chewing Simulator with Thermocycler; Alexandria, Egypt

${ }^{11}$ Instron Model 3345; Instron Industrial Products, Norwood, USA

${ }^{12}$ Bluehill Lite; Instron Instruments
} 
Retention Strength of Polyetheretherketone Crowns VS Zirconia Crowns Restoring Molar Teeth: An in Vitro Study

Mohammad et al

Volume 2 issue 1

Failure mode observation: After dislodgement, the debonded surfaces of the resin dies and their crown intaglios were inspected using a USB digitalmicroscope ${ }^{13}$. The images were captured and then transferred to IBM personal computer equipped with the Image-tool software ${ }^{14}$ to determine the failure mode, according to the location of the remaining cement on the debonded surfaces. The collected data were tabulated and statistically analyzed with three-way ANOVA. Pair-wise comparison of groups was made with the Tukey test. The mode of failure was analyzed with Pearson's Chi-Square test $(\boldsymbol{\alpha}=\mathbf{0 . 0 5})$. The statistical analysis was done with the support of the Institute of Medical Information and Statistic, Christian-Albrechts University, Kiel. A P-value of $\mathbf{0 . 0 5}$ or more was considered insignificant.

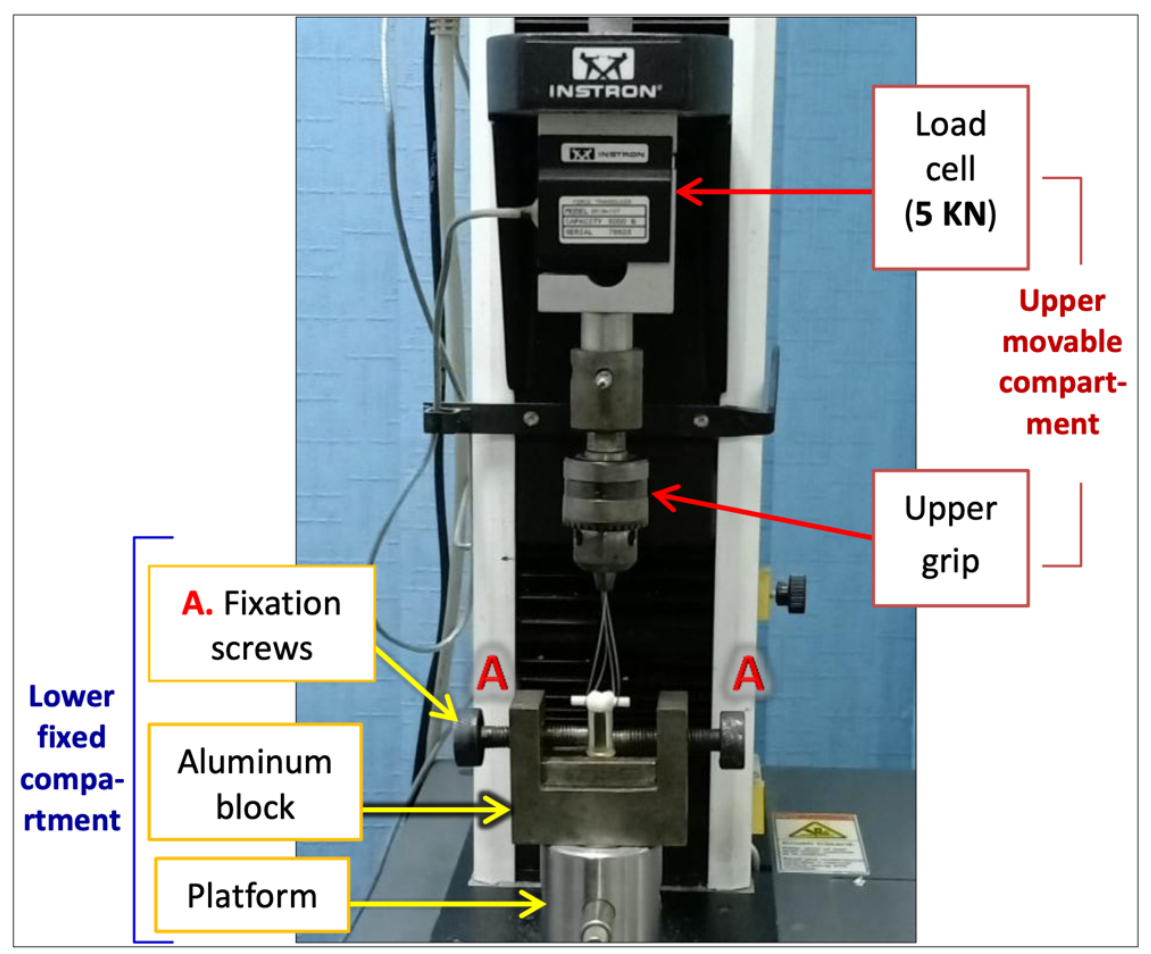

Figure 5: UTM (Consisting of two compartments) during pull off test

\footnotetext{
${ }^{13}$ U500X Digital Microscope; Guangdong, China

${ }^{14}$ Image J 1.43U, National Institute of Health, USA
} 


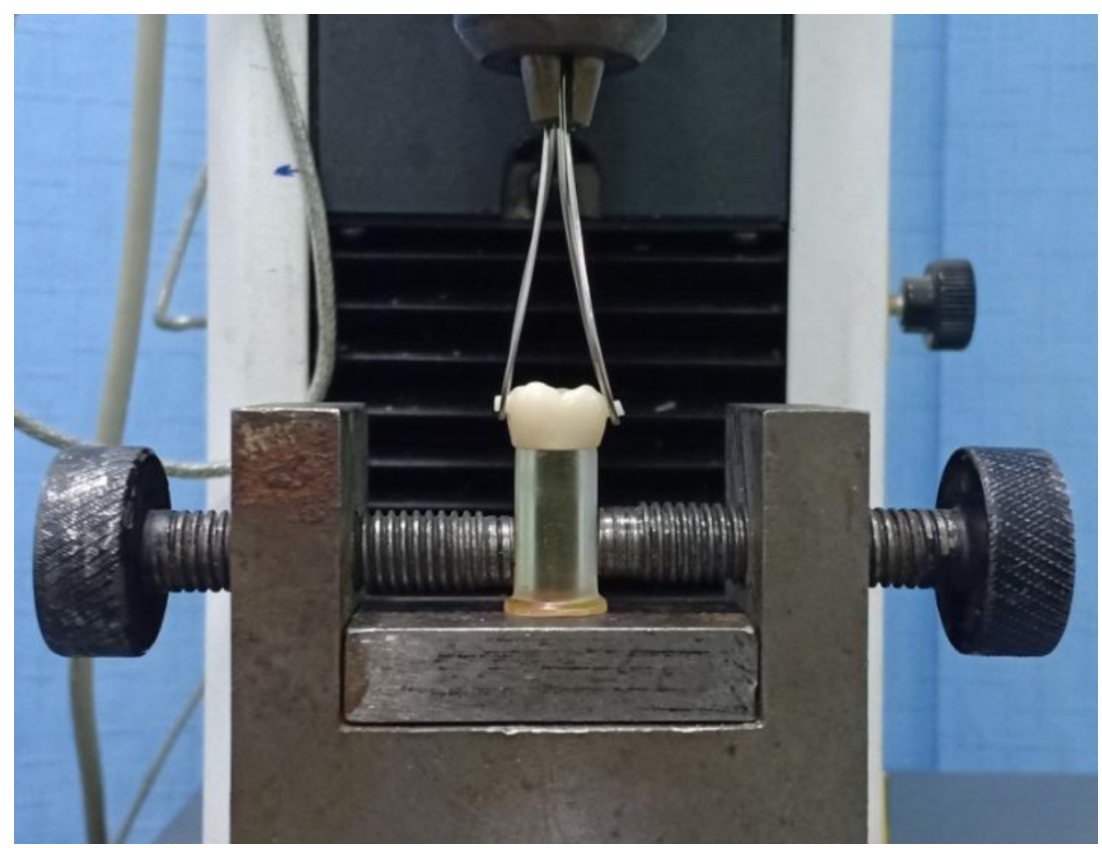

Figure 6: Specimen fixed in lower compartment, crown attached to upper compartment through its lateral arms via double orthodontic wire

\section{Results:}

Retention strength results: Data were presented as mean, standard deviation (SD), range (Minimum - Maximum) for values. Data were explored for normality by checking the data distribution and using Kolmogorov-Smirnov and ShapiroWilk tests. Student t-test was used to compare mean values. The significance level was set at $\mathrm{P}$ and $\mathbf{9 5 \%}$ Confidence Interval. $\mathrm{P}$ value $\leq \mathbf{0 . 0 5}$ was considered significant. Statistical analysis was performed using Graph Pad Instat (Graph Pad, Inc.) software for windows.

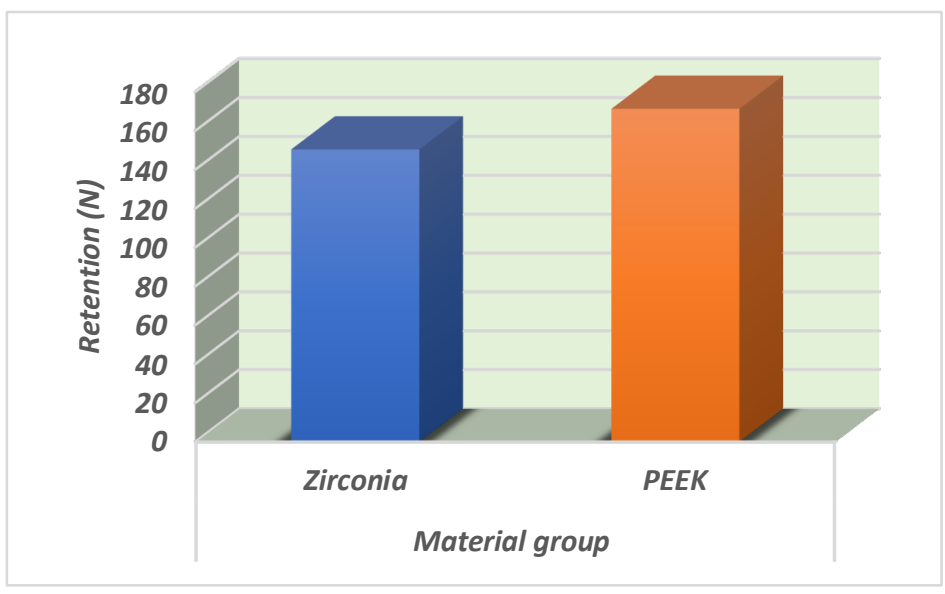

Fig. 7. Column chart showing retention mean values for both groups 
Retention Strength of Polyetheretherketone Crowns VS Zirconia Crowns Restoring Molar Teeth: An in Vitro Study

Mohammad et al

Volume 2 issue 1

Descriptive statistics of retention (N) showing mean, standard deviation (SD), minimum, maximum and 95\% confidence intervals (low and high) values for both groups are summarized in Table 1, and graphically represented in Fig. 7. It was found that $\boldsymbol{P E E K}$ crowns group recorded statistically insignificant higher retention mean value (171.28 $\mathbf{N} \pm 26.30)$ than Zirconia crowns group $(\mathbf{1 5 0 . 4 0} \mathbf{N}$ $\pm 24.40)$ as indicated by t-test $(\mathbf{P}=\mathbf{0 . 0 6 7 9}>0.05)$, as shown in Table 1 and Fig. 7.

\begin{tabular}{|c|c|c|c|c|c|c|c|}
\hline \multirow{2}{*}{\multicolumn{2}{|c|}{ Variables }} & \multirow{3}{*}{$\begin{array}{r}\text { Mean } \pm \boldsymbol{S D} \\
\mathbf{1 5 0 . 4 0} \\
\pm 24.40\end{array}$} & \multirow{3}{*}{$\begin{array}{r}S E M \\
7.35\end{array}$} & \multirow{3}{*}{$\begin{array}{c}\text { Median } \\
149.23\end{array}$} & \multicolumn{2}{|c|}{$95 \% C I$} & \multirow{2}{*}{$\begin{array}{l}\text { Statistics } \\
\text { P value }\end{array}$} \\
\hline & & & & & Low & High & \\
\hline \multirow{2}{*}{$\begin{array}{l}\text { Material } \\
\text { group }\end{array}$} & Zirconia & & & & 115.29 & 184.94 & \multirow{2}{*}{$\begin{array}{c}.06794 \\
\text { Ns }\end{array}$} \\
\hline & PEEK & $\begin{array}{l}\mathbf{1 7 1 . 2 8} \\
\pm 26.30\end{array}$ & 7.92 & 184.12 & 129.29 & 198.74 & \\
\hline
\end{tabular}

Table 1. Comparison of retention results (Mean values \pm SD) and $P$ value between both groups

$$
\text { *; significant }(\mathrm{p}<0.05) \quad \text { ns; non-significant }(\mathrm{p} \geq 0.05)
$$

Table 2. Categories for characterization of failure type after crown dislodgment

\begin{tabular}{ccc}
\hline Classification & Description & Nature \\
\hline Category 1 & $\begin{array}{c}\text { Cement mainly } \\
\text { on the crown } \\
\text { intaglio }\end{array}$ & $\begin{array}{c}\text { Adhesive } \\
\text { (cement on- } \\
\text { crown) }\end{array}$ \\
Category 2 & $\begin{array}{c}\text { Cement mainly } \\
\text { on the die }\end{array}$ & $\begin{array}{c}\text { Adhesive } \\
\text { (cement on- } \\
\text { die) }\end{array}$ \\
Category 3 & Mixed & $\begin{array}{c}\text { Adhesive } \\
\text { (mixed) }\end{array}$ \\
\hline
\end{tabular}

\section{Failure modes results:}

Failure modes were categorized according to the site of the remaining cement, as described by Shahin and Kern (2010) ${ }^{[16]}$, as shown in the following Table 2:

The "mixed" mode of failure was the predominant in both groups. The category of failure mode specified for each specimen is shown in Table 3 . The results of failure-mode analysis are shown in Table 3 and Fig. 8. 
Retention Strength of Polyetheretherketone Crowns VS Zirconia Crowns Restoring Molar Teeth: An in Vitro Study

Mohammad et al

Volume 2 issue 1

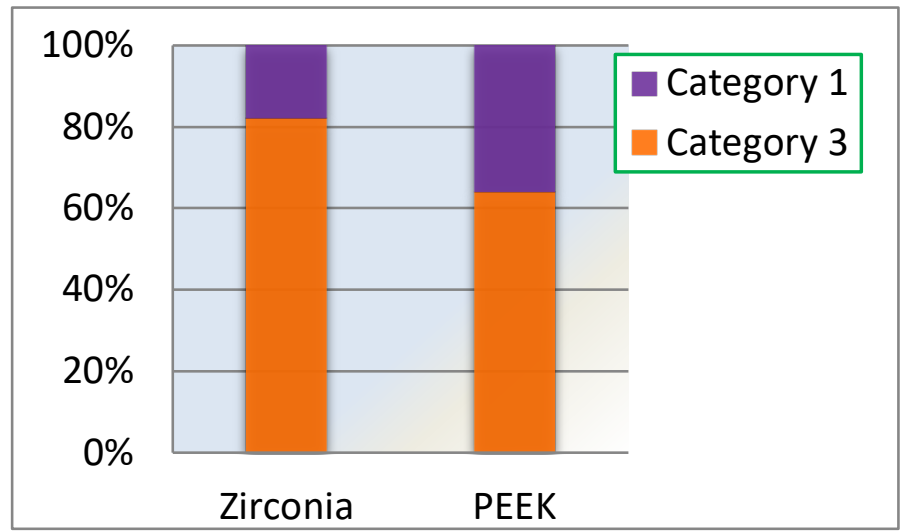

Fig. 8. Frequency of failure modes in both groups Category 1: "Cement-on-crown" failure mode Category 3: Mixed failure mode

\begin{tabular}{|c|c|c|c|}
\hline Group & $\begin{array}{l}\text { Category } 1 \\
\text { "Cement } \\
\text { on-crown" }\end{array}$ & $\begin{array}{l}\text { Category } 2 \\
\text { "Cement on- } \\
\text { die" }\end{array}$ & $\begin{array}{c}\text { Category } 3 \\
\text { "Mixed" }\end{array}$ \\
\hline $\begin{array}{c}\mathrm{Zr} \\
(\mathrm{n}=11)\end{array}$ & $\begin{array}{c}2 \\
(18 \%)\end{array}$ & 0 & $\begin{array}{c}9 \\
(82 \%)\end{array}$ \\
\hline $\begin{array}{c}P \\
(n=11)\end{array}$ & $\begin{array}{c}4 \\
(36 \%)\end{array}$ & 0 & $\begin{array}{c}7 \\
(64 \%)\end{array}$ \\
\hline
\end{tabular}

Table 3. Frequency of failure modes in each group after debonding.

Number of specimens (\%) for each category of failure in both groups, according to location of remaining cement 


\begin{tabular}{|c|c|c|c|}
\hline \multirow{2}{*}{\multicolumn{2}{|c|}{ Variables }} & \multicolumn{2}{|c|}{ Failure mode } \\
\hline & & \multirow{2}{*}{$\begin{array}{c}\begin{array}{c}\text { Category } \mathbf{1} \\
\text { (Cement on- } \\
\text { crown) }\end{array} \\
\mathbf{2}(18 \%) \\
\end{array}$} & \multirow{2}{*}{$\begin{array}{c}\begin{array}{c}\text { Category } \\
\text { (Mixed) }\end{array} \\
11 \quad(82 \%)\end{array}$} \\
\hline \multirow{2}{*}{$\begin{array}{c}\text { Material } \\
\text { group }\end{array}$} & Zirconia & & \\
\hline & PEEK & $4 \quad(36 \%)$ & $7 \quad(64 \%)$ \\
\hline \multirow{2}{*}{$\begin{array}{c}\text { Chi- } \\
\text { squared } \\
\text { test }\end{array}$} & $\begin{array}{c}\text { Chi- } \\
\text { square } \\
\text { statistic }\end{array}$ & \multicolumn{2}{|c|}{8.2192} \\
\hline & $P$ value & \multicolumn{2}{|c|}{$0.004145^{*}$} \\
\hline \multicolumn{4}{|c|}{ *: Significant $(P<0.05)$} \\
\hline
\end{tabular}

Table 4. Comparison of frequency of distribution of failure modes (\%) between the two material groups

Pearson's Chi-squared $\left(\mathrm{X}^{2}\right)$ test was used to compare the failure mode frequencies for both groups as shown in Table 4 .

The results showed a significant difference $(\mathbf{P}<\mathbf{0 . 0 5})$ in the frequency of failure modes between the two groups. "Mixed" mode of failure is more likely to occur with zirconia crowns, while "cement on-crown" failure mode is more likely to occur in PEEK than zirconia.

\section{Discussion:}

PEEK; being quite new in the field of prosthodontics, compared to zirconia is a lower cost material with comparable mechanical properties, which can be more easily repaired within the mouth, and does not wear down in oral conditions. On top of this, it has a significantly more matching modulus of elasticity to the tooth [10]. Such advantages make it an attractive and even competitive candidate, with zirconia, for FDPs ${ }^{[17]}$. Hence, this study has aimed to evaluate the performance of $\mathrm{CAD} / \mathrm{CAM}$ monolithic PEEK crowns vs. CAD/CAM monolithic zirconia crowns, with regards to their retention strength to epoxy dies, after thermomechanical aging simulating 3 months of clinical service. Air-borne particle abrasion by $\mathbf{1 1 0}-\boldsymbol{\mu m}$ alumina particles at $0.2 \mathrm{MPa}$ pressure was chosen for both groups for standardization purpose. It was also recommended by the manufacturers of both materials and was proven by many studies to provide the best surface roughness, retention, as well as shear bond strength results ${ }^{[14,16,18]}$. Standardization of surface treatment, as well as other retention affecting factors like preparation criteria and cement type, between both groups was intended to better assess the contribution of the material itself to retention. The chosen cement 
Retention Strength of Polyetheretherketone Crowns VS Zirconia Crowns Restoring Molar Teeth: An in Vitro Study

RelyX ${ }^{\mathrm{TM}}$ U200 is both MDP- and MMA-containing. Many authors claimed that the use of materials containing MDP is a key to obtaining satisfactory adhesion of the resin cement to zirconia, because MDP directly connects to metal oxides [8,19]. Also, MMA monomer-containing adhesive systems, especially after sandblasting, are generally recommended to enhance the bond strength with PEEK material even after aging ${ }^{[20-21]}$. These acidic monomers are believed to copolymerize with the industrially polymerized CAD/CAM resin ${ }^{[22]}$.

The use of chewing simulators with additional artificial aging through thermocycling is a well-proven method to simulate the various clinical conditions in vitro, owing to their standardization and reproducibility ${ }^{[20,23]}$. The number of thermodynamic loading (TDL) cycles, representing 3 months of service, was chosen as an average for testing the longevity of service of ceramic crowns ${ }^{[13]}$.

The application of tensile pull-out force on a crown is considered a logical, reproducible and reliable method to test the retentive strength of a crown to its underlying abutment as stated by Heintze (2010) ${ }^{[24]}$ and Keul et al. (2014) ${ }^{[25]}$.

Regarding the effect of the material type on the retention strength, results showed that PEEK material recorded higher mean retention values $(\mathbf{1 7 1 . 2 8} \mathrm{N} \pm \mathbf{2 6 . 3 0})$ than zirconia (150.40 $\mathbf{N} \pm \mathbf{2 4 . 4 0})$. However, the results were statistically insignificant. These data support the previously postulated hypothesis for this study.

The mean dislodgment force in our study for "Zr" crowns group (150.40 N), was in accordance with another study by Sayed et al. (2017) ${ }^{[14]}$ that used similar methodology $(114.09 \mathrm{~N}-166.19 \mathrm{~N})$. Yet, the mean dislodgment values for zirconia crowns in other studies were in different range from the current study $(230 \mathrm{~N}-648 \mathrm{~N})^{[15,16]}$. Those had a completely different methodology from the present study; and they cemented zirconia on natural teeth (molars or premolars) instead of resin dies. Changing the substrate from natural teeth and resin dies is believed to have an effect on retention ${ }^{[26]}$.

The mean dislodgment force for "P" crowns group was 171.28 N. This could be compared to the study done by Uhrenbacher et al. (2014) ${ }^{[20]}$, who concluded that the adhesion of the tested PEEK crowns to dentin was satisfactory (2.12-2.97 MPa) after treatment with airborne-particle abrasion and bonding with MMAcontaining adhesive systems.

Based on the retention strength results of Sayed et al. (2017) ${ }^{[14]}$ and Amarnath et al. (2015) $)^{[27]}$, which are comparable to ours, the current results could be considered clinically acceptable. This could be attributed to the optimum retention criteria that were considered throughout the study; including the preparation design ${ }^{[24]}$, adequate surface treatment for both materials ${ }^{[11]}$, as well as the use of an MDP- and MMA- containing resin cement (RelyX ${ }^{\mathrm{TM}}$ U200). Nonetheless, our results regarding PEEK vs. zirconia were contradicting with those of the previously mentioned study of PEEK retention by Uhrenbacher et al. (2014) ${ }^{[20]}$, which concluded that zirconia had significantly higher retention results (7.3-14.1 MPa) than PEEK (0.4-2.9 MPa). The difference of these results 
Retention Strength of Polyetheretherketone Crowns VS Zirconia Crowns Restoring Molar Teeth: An in Vitro Study

from ours might be due to difference in zirconia and PEEK brands from the current study. The ceramic composition and intaglio surfaces are specific for each commercial system; thus, conclusions drawn for one zirconia ceramic system may not apply to others ${ }^{[20,28]}$.

The most frequent failure mode for "Zr" group was "mixed" failure (cat. 3) by $\mathbf{8 2 \%}$; while the remaining $18 \%$ demonstrated adhesive "cement on-crown" (cat. 1) failure mode (Table 3 \& Fig. 8). That was in accordance with Aleisa et al. $(2013)^{[15]}$ and Stawarczyk et al. (2012) ${ }^{[22]}$. It indicates high bonding strength of the resin cement to both zirconia crowns and the die material. This might be attributed to the adequate surface treatment of zirconia by sandblasting, and the use of MDP-containing resin cement.

The "mixed" failure mode was also dominant for "P" group by $64 \%$, while the remaining $36 \%$ of the samples showed the adhesive "cement-on-crown" failure mode (Table 3 \& Fig. 8). That was in agreement with Uhrenbacher et al. $(2014)^{[20]}$.

For both groups, the prevalent mixed mode of failure is explained as a cohesive failure in the cement; indicating a high bond strength ${ }^{[16]}$. It was assumed that the bond strength to both the crown and epoxy die was higher than the tensile strength of the cement. Generally, the dominance of "mixed" and "on-crown" failure modes along with the absence of "cement on-die" mode, in both groups, declare a reliable and comparable bond for both materials.

PEEK crowns have shown significantly higher prevalence of "on-crown" failure mode than zirconia according to Pearson's chi-squared test analysis (Table 4). The higher retention values for PEEK, together with the significantly higher occurrence of "on-crown" failure modes than zirconia, could be justified by a possible chemical bond that could have happened between the resin cement and functional groups of PEEK, considering they are both polymers ${ }^{[20]}$. This might be attributed to the depth of irregularities induced by air-borne particle abrasion of PEEK surface, which could have been more convenient for interlocking with cement than zirconia due to its lower hardness. This might have led to enhanced surface energy, and hence rendered a better wettability by the cement ${ }^{[25,29]}$. According to Hallman et al. (2012) ${ }^{[30]}$ who studied the effect of air-abrasion on shear bond strength of PEEK under SEM, the surface structure originating from the air abrasion improved the mechanical anchorage of the adhesive to PEEK surface, due to the penetration of adhesive inside of the polymer. The mechanical bonds which occur in this case, according to them are very strong and stable. Limitations of this study include the lack of prolonged long-term results, which were not obtained because the water storage time was limited to 1 day, and the thermomechanical aging period was merely corresponding to three months of invivo service.

Conclusions: Within the limitations of the present study, the following can be concluded: 1. CAD/CAM PEEK crowns showed statistically non-significant superior retention values to $\mathrm{CAD} / \mathrm{CAM}$ zirconia crowns, after thermomechanical 
Retention Strength of Polyetheretherketone Crowns VS Zirconia Crowns Restoring Molar Teeth: An in Vitro Study

aging simulating 3 months of clinical service. 2. The retention strength values of both tested materials are considered to be clinically acceptable. 3. PEEK represents a competitive candidate with zirconia for fixed prosthodontics, particularly in terms of retention.

\section{References:}

1- SILVA, L. H. D., LIMA, E. D., MIRANDA, R. B. D. P., Favero, S. S., Lohbauer, U., \& Cesar, P. F. (2017). Dental ceramics: a review of new materials and processing methods. Brazilian oral research, 31 .

2- da Silva, L. H., de Lima, E., Hochman, M., Özcan, M., \& Cesar, P. F. (2017). Monolithic Zirconia for Prosthetic Reconstructions: Advantages and Limitations. Current Oral Health Reports, 4(3), 197-200.

3- bredent GmbH \& Co. KG. (2015) BioHPPTM: The reference for physiological substructure material. Germany.

4- Gutiérrez-Salazar, M. D. P., \& Reyes-Gasga, J. (2003). Microhardness and chemical composition of human tooth. Materials Research, 6(3), 367-373.

5- Ito, Y., Sugita, N., Fujii, T., Kizaki, T., \& Mitsuishi, M. (2017). Precision Machining of Sintered Zirconia Ceramics by High-Speed Milling. International Journal of Automation Technology, 11(6), 862-868.

6- Malkondu, Ö., Tinastepe, N., Akan, E., \& Kazazoğlu, E. (2016). An overview of monolithic zirconia in dentistry. Biotechnology \& biotechnological equipment, 30(4), 644-652.

7- Özkurt-Kayahan, Z. (2016). Monolithic zirconia: A review of the literature. Biomed Res, 27(4), 1427-1436.

8- Xie, H., Tay, F. R., Zhang, F., Lu, Y., Shen, S., \& Chen, C. (2015). Coupling of 10-methacryloyloxydecyldihydrogenphosphate to tetragonal zirconia: Effect of $\mathrm{pH}$ reaction conditions on coordinate bonding. Dental Materials, 31(10), e218-e225.

9- Blatz, M. B., Sadan, A., \& Kern, M. (2003). Resin-ceramic bonding: a review of the literature. The Journal of prosthetic dentistry, 89(3), 268-274.

10- Kurtz, S. M., \& Devine, J. N. (2007). PEEK biomaterials in trauma, orthopedic, and spinal implants. Biomaterials, 28(32), 4845-4869.

11- Zidan, O., \& Ferguson, G. C. (2003). The retention of complete crowns prepared with three different tapers and luted with four different cements. The Journal of prosthetic dentistry, 89(6), 565-571.

12- Prasad K., Hegde C., and Desai H. (2017), A Survey to Assess The Failures In Fixed Partial Dentures. Int J Recent Sci Res. 8(7), pp. 18770-18773

13- Güngör, M. B., Nemli, S. K., Bal, B. T., Tamam, E., Yılmaz, H., \& Aydın, C. (2019). Fracture resistance of monolithic and veneered all-ceramic four-unit posterior fixed dental prostheses after artificial aging. Journal of oral science, 18-0060.

14- Sayed, A., Gomaa, Y. F., \& Mohsen, S. A. (2017). Effect of Surface Treatment and Type of Resin Cement on Retentive Force of Zirconia Crowns. A Comparative In Vitro Study. EC Dental Science, 13, 245-251. 
Retention Strength of Polyetheretherketone Crowns VS Zirconia Crowns Restoring Molar Teeth: An in Vitro Study

15- Aleisa, K., Alwazzan, K., Al-Dwairi, Z. N., Almoharib, H., Alshabib, A., Aleid, A., \& Lynch, E. (2013). Retention of zirconium oxide copings using different types of luting agents. Journal of Dental Sciences, 8(4), 392-398.

16- Shahin, R., \& Kern, M. (2010). Effect of air-abrasion on the retention of zirconia ceramic crowns luted with different cements before and after artificial aging. Dental materials, 26(9), 922-928.

17- Tekin, S., Cangül, S., Adıüzel, Ö., \& Değer, Y. (2018). Areas for use of PEEK material in dentistry. International Dental Research, 8(2), 84-92.

18- Su, N., Yue, L., Liao, Y., Liu, W., Zhang, H., Li, X., ... \& Shen, J. (2015). The effect of various sandblasting conditions on surface changes of dental zirconia and shear bond strength between zirconia core and indirect composite resin. The journal of advanced prosthodontics, 7(3), 214-223.

19- Nagaoka, N., Yoshihara, K., Feitosa, V. P., Tamada, Y., Irie, M., Yoshida, Y., ... \& Hayakawa, S. (2017). Chemical interaction mechanism of 10-MDP with zirconia. Scientific reports, 7(1), 1-7.

20- Uhrenbacher, J., Schmidlin, P. R., Keul, C., Eichberger, M., Roos, M., Gernet, W., \& Stawarczyk, B. (2014). The effect of surface modification on the retention strength of polyetheretherketone crowns adhesively bonded to dentin abutments. The Journal of prosthetic dentistry, 112(6), 1489-1497.

21- Stawarczyk, B., Keul, C., Beuer, F., Roos, M., \& Schmidlin, P. R. (2013). Tensile bond strength of veneering resins to PEEK: impact of different adhesives. Dental materials journal, 32(3), 441-448.

22- Stawarczyk, B., Basler, T., Ender, A., Roos, M., Özcan, M., \& Hämmerle, C. (2012). Effect of surface conditioning with airborne-particle abrasion on the tensile strength of polymeric $\mathrm{CAD} / \mathrm{CAM}$ crowns luted with self-adhesive and conventional resin cements. The Journal of prosthetic dentistry, 107(2), 94101.

23- Palmer, D. S., Barco, M. T., \& Billy, E. J. (1992). Temperature extremes produced orally by hot and cold liquids. The Journal of prosthetic dentistry, 67(3), 325-327.

24- Heintze, S. D. (2010). Crown pull-off test (crown retention test) to evaluate the bonding effectiveness of luting agents. Dental materials, 26(3), 193-206.

25- Keul, C., Liebermann, A., Schmidlin, P. R., Roos, M., Sener, B., \& Stawarczyk, B. (2014). Influence of PEEK surface modification on surface properties and bond strength to veneering resin composites. J Adhes Dent, 16(4), 383-92.

26- Oilo, G. (1993). Bond strength testing--what does it mean?. International dental journal, 43(5), 492-498.

27- Amarnath, G. S., Pandey, A., Prasad, H. A., \& Hilal, M. (2015). Comparative evaluation of enhancing retention of dislodged crowns using preparation modifications and luting cements: An in-vitro study. Journal of international oral health: $\mathrm{JIOH}, 7(8), 47$. 
28- Karimipour-Saryazdi, M., Sadid-Zadeh, R., Givan, D., Burgess, J. O., Ramp, L. C., \& Liu, P. R. (2014). Influence of surface treatment of yttrium-stabilized tetragonal zirconium oxides and cement type on crown retention after artificial aging. The Journal of prosthetic dentistry, 111(5), 395-403.

29- Inokoshi, M., De Munck, J., Minakuchi, S., \& Van Meerbeek, B. (2014). Meta-analysis of bonding effectiveness to zirconia ceramics. Journal of dental research, 93(4), 329-334.

30- Hallmann, L., Mehl, A., Sereno, N., \& Hämmerle, C. H. (2012). The improvement of adhesive properties of PEEK through different pretreatments. Applied Surface Science, 258(18), 7213-7218. 